\title{
Summary of recommendations for the diagnosis and treatment of malaria by the Committee to Advise on Tropical Medicine and Travel (CATMAT)
}

\author{
Boggild $A^{1}$, Brophy $\mathrm{J}^{2}$, Charlebois $\mathrm{P}^{3}$, Crockett $\mathbf{M}^{4}$, Geduld $\mathrm{J}^{5}$, Ghesquiere $\mathbf{W}^{6}$, McDonald $\mathrm{P}^{7}$, \\ Plourde $\mathrm{P}^{8}$, Teitelbaum $\mathrm{P}^{9}$, Tepper $\mathrm{M}^{10}$, Schofield $\mathrm{S}^{11}$ and McCarthy $\mathrm{A}$ (Chair) ${ }^{12^{\star}}$ \\ 1 University Health Network, Toronto General Hospital (Toronto, ON) \\ 2 Division of Infectious Diseases, Children's Hospital of Eastern Ontario (Ottawa, ON) \\ 3 Internal Medicine, Canadian Forces Health Services Centre (Atlantic) (Halifax, NS) \\ 4 Paediatrics and Child Health, University of Manitoba (Winnipeg, MB) \\ 5 Infectious Disease Prevention and Control Branch, Public Health Agency of Canada (Ottawa, ON) \\ 6 Infectious Diseases and Internal Medicine, University of British Columbia (Victoria, BC) \\ 7 Therapeutic Products Directorate, Health Canada (Ottawa, ON) \\ 8 Faculty of Medicine, University of Manitoba (Winnipeg, MB) \\ 9 Riverside Travel Medicine Clinic (Ottawa, ON) \\ ${ }^{10}$ Communicable Disease Control Program, Directorate of Force Health Protection (Ottawa, ON) \\ ${ }^{11}$ Pest Management Entomology, Directorate of Forces Health Protection (Ottawa, ON) \\ ${ }^{12}$ Tropical Medicine and International Health Clinic, Division of Infectious Disease, Ottawa Hospital General Campus \\ (Ottawa, ON) \\ * Corresponding author: AMcCARTHY@Ottawahospital.on.ca
}

\begin{abstract}
Background: On behalf of the Public Health Agency of Canada, the Committee to Advise on Tropical Medicine and Travel (CATMAT) developed the Canadian Recommendations for the Prevention and Treatment of Malaria Among International Travellers for Canadian health care providers who are preparing patients for travel to malaria-endemic areas and treating travellers who have returned ill. These recommendations aim to achieve appropriate diagnosis and management of malaria, a disease that is still uncommon in Canada.
\end{abstract}

Objective: To provide recommendations on the appropriate diagnosis and treatment of malaria.

Methods: CATMAT reviewed all major sources of information on malaria diagnosis and treatment, as well as recent research and national and international epidemiological data, to tailor guidelines to the Canadian context. The evidence-based medicine recommendations were developed with associated rating scales for the strength and quality of the evidence.

Recommendations: Malarial management depends on rapid identification of the disease, as well as identification of the malaria species and level of parasitemia. Microscopic identification of blood samples is both rapid and accurate but can be done only by trained laboratory technicians. Rapid diagnostic tests are widely available, are simple to use and do not require specialized laboratory equipment or training; however, they do not provide the level of parasitemia and do require verification. Polymerase chain reaction (PCR), although still limited in availability, is emerging as the gold standard for high sensitivity and specificity in identifying the species.

Severe or complicated malaria requires admission to hospital for regular monitoring of respiratory rate and pattern, coma score, and glucose and urine output, especially if the patient is unconscious. In high levels of parasitemia, exchange transfusion may be beneficial to remove infected red blood cells and toxic mediators from the circulation, and reduce the parasite load. Because of the elevated risk of severe or complicated malaria, those with a diagnosis of Plasmodium falciparum malaria should also be admitted to hospital or receive initial treatment in an observation unit. 
Uncomplicated malaria is treated to cure the infection and prevent progression to severe disease. When treatment regimens are being chosen, drug tolerability, the adverse effects of drugs and the speed of therapeutic response should be considered.

\section{Introduction}

Malaria is a serious infection caused by five different species of the genus Plasmodium: falciparum, vivax, ovale, malariae and knowlesi. Malaria is transmitted by the bite of infected female anopheline mosquitoes. Infections caused by $P$. falciparum have the highest fatality rates. The overall case-fatality rate of falciparum malaria varies from about $1 \%$ to $5 \%$ and increases to $20 \%$ for those with severe malaria (1-2).

According to the World Health Organization (WHO), about 3.3 billion people were at risk of malaria in 2010, resulting in an estimated 219 million cases, of which about $80 \%$ occurred in 17 countries and of which about $40 \%$ were in India, Nigeria and the Democratic Republic of Congo (3). Malaria is still diagnosed in Canada following travel in endemic countries. The Canadian Notifiable Diseases Surveillance System, which monitors nationally notifiable infectious diseases, received reports of 4,254 cases of malaria from 2001 to 2011 (D.Taylor, Public Health Agency of Canada, unpublished data, 2013).

From August 2001 to August 2012, the Canadian Malaria Network, which facilitates rapid access to parenteral treatment of severe malaria, received reports of 195 cases of severe or complicated malaria (personal communication, A. McCarthy and J. Geduld, Committee to Advise on Tropical Medicine and Travel, 2012).

The most important factors determining patient survival are early diagnosis and appropriate therapy. The majority of malaria deaths are preventable and are frequently the result of delays in diagnosis and treatment. Among the cases reported to the Canadian Malaria Network, only 20\% presented to medical care within 24 hours of onset of symptoms, and $44 \%$ waited more than three days (personal communication, A. McCarthy and J. Geduld, K. Cullen and P. Arguin, US Centers for Disease Control and Prevention, 2012). Diagnosis by health care provider was delayed more than 24 hours in $34 \%$ of the cases (personal communication, A. McCarthy and J. Geduld, 2012).

This is a summary of the CATMAT Canadian Recommendations for the Prevention and Treatment of Malaria Among International Travellers, developed for Canadian health care providers who are preparing patients for travel to malaria-endemic areas and treating travellers who have returned ill (4). These guidelines include a full description of recommendations on diagnosis and treatment of malaria.

\section{Methods}

The Malaria Subcommittee, a working group of CATMAT, developed the guidelines. The process undertaken to develop them has been described previously (5). It included a review of recent research and national and international epidemiological data, and the consideration of other factors, such as malaria epidemiology, and the anticipated values and preferences of travellers and health care providers. The evidence-based medicine recommendations for the diagnosis and treatment of malaria were developed with associated rating scales for the strength and quality of the evidence. 


\section{Recommendations}

The evidence-based CATMAT recommendations for malaria diagnosis and treatment are summarized in Table 1. A discussion of some of the key recommendations follows.

Table 1: Evidence-based medicine recommendations for the diagnosis and treatment of malaria

\begin{tabular}{l|c}
\hline Recommendation & EBM $^{1}$ rating \\
\hline $\begin{array}{l}\text { Parenteral artesunate is recommended as first-line treatment for severe } P \text {. falciparum } \\
\text { malaria, with parenteral quinine as an alternative (3). }\end{array}$ & A I \\
\hline $\begin{array}{l}\text { To prevent relapses of } P \text {. vivax and } P \text {. ovale malaria, primaquine phosphate }(30 \mathrm{mg} \\
\text { base daily for } 2 \text { weeks) should follow chloroquine treatment (6). }\end{array}$ & B I \\
\hline
\end{tabular}

3. The treatments of choice for uncomplicated $P$. falciparum malaria are as follows:

- Oral chloroquine (ONLY if from chloroquine-sensitive areas);

- Oral atovaquone-proguanil (7);

- Oral quinine combined with oral doxycycline or clindamycin;

- Combination therapy with an artemisinin derivative (not yet available in Canada) (7).

4. Exchange transfusion may have benefits for treating hyperparasitemic cases of P. falciparum (8).

5. Individuals in chloroquine-sensitive regions should self-treat with chloroquine and then resume or start chloroquine prophylaxis (9-11).

6. In chloroquine- and/or chloroquine- and mefloquine-resistant $P$. falciparum regions, self-treatment should consist of a drug different to that used for prophylaxis, chosen from one of the following:

a. atovaquone-proguanil (Malarone ${ }^{\circledR}$ ) or

b. oral quinine and doxycycline or

c. artemether-lumefantrine $\left(\right.$ Coartem $\left.^{\circledR}\right)$, ideally purchased from a country with high standards of quality control (e.g. in Europe or the United States) so as to minimize the likelihood of using counterfeit products (10-13).

7. The use of steroids to treat severe or cerebral malaria has been associated with worse outcomes and should be avoided (14).

8. A number of antimalarials are contraindicated in the treatment of malaria (selftreatment or otherwise):
a) mefloquine (15)
b) pyrimethamine-sulfadoxine (Fansidar) (16)
c) mefloquine-Fansidar (17)
d) halofantrine (7)
e) chloroquine-Fansidar (18).

${ }^{1} \mathrm{EBM}=$ Evidence based medicine. The EBM ratings are as follows:

Strength of recommendation:

$A=$ Good evidence to support a recommendation for use

$B=$ Moderate evidence to support a recommendation for use

$C=$ Poor evidence to support a recommendation for or against use

$D=$ Moderate evidence to support a recommendation against use

$E=$ Good evidence to support a recommendation against use

Quality of evidence:

$I=$ Evidence from at least one properly randomized, controlled trial

$\mathrm{II}=$ Evidence from at least one well-designed clinical trial without randomization; from cohort or case-controlled analytic studies, preferably from more than one centre; from multiple time series; or from dramatic results in uncontrolled experiments

III = Evidence from opinions of respected authorities on the basis of clinical experience, descriptive studies, or reports of expert committees 


\section{Malaria Diagnosis}

Malaria could be the reason for any etiologically unidentified fever that develops while a traveller is in a malariaendemic area or up to one year after leaving, irrespective of chemoprophylaxis use (19). If a fever occurs during this time, the traveller should seek medical attention immediately and tell the health care provider about his/her travel history. Particular attention should be paid to fevers that develop in the three months following travel, as more than $90 \%$ of falciparum malaria presents during this period.

Since the disease can progress from asymptomatic infection to severe and complicated malaria and even death within 36 to 48 hours, survival of patients particularly with $P$. falciparum malaria (20) is affected by early diagnosis and correct speciation to determine the required life-saving treatment. Quantitating parasitemia is also important to determine the need for parenteral treatment, for exchange transfusion or for admission to an intensive care unit (ICU). In addition, it is important for monitoring response to treatment.

Microscopy, which involves examining thick and thin blood smears, is both rapid and accurate. A Canadian laboratory should be able to confirm the presence of a parasite and, in most cases, identify the species within one to two hours of receiving a blood specimen (21-24). However, accurate examination of a blood smear requires considerable training and experience $(23,25)$.

Rapid diagnostic tests are simple to use and do not require any specialized laboratory equipment or skills. They are essential diagnostic tools if malaria microscopy results are not available within two hours (26). However, both positive and negative results must be verified by expert microscopy or PCR to determine the level of parasitemia and to identify the species. Note that the use of rapid diagnostic tests by travellers to self-diagnose is unreliable.

Although still limited in its availability, PCR is emerging as the gold standard for high sensitivity and specificity in speciation. It is being increasingly used for quality control (27-29).

\section{General principles of malaria management}

When managing malaria, three questions need to be answered:

\section{1) Is this infection caused by P. falciparum?}

Treatment varies according to the species of malaria. $P$. falciparum can cause life-threatening disease in a nonimmune host and is a medical emergency. Consider hospital admission for all nonimmune cases and for all children to ensure that antimalarial drugs are tolerated and to detect complications or early treatment failure.

\section{2) Is this severe or complicated malaria?}

In a case of $P$. falciparum and no other obvious cause of symptoms, having one or more of the following clinical or laboratory features indicates severe or complicated malaria:

\begin{tabular}{|l|l|}
\hline Clinical manifestation & Laboratory test \\
\hline Prostration/impaired consciousness & Severe anemia (hematocrit $<15 \% ; \mathrm{Hb} \leq 50 \mathrm{~g} / \mathrm{L}$ ) \\
\hline Respiratory distress & Hypoglycemia (blood glucose $<2.2 \mathrm{mmol} / \mathrm{L})$ \\
\hline Multiple convulsions & Acidosis (arterial $\mathrm{pH}<7.25$ or bicarbonate $<15 \mathrm{mmol} / \mathrm{L})$ \\
\hline Circulatory collapse & Renal impairment (creatinine $>265 \mathrm{umol} / \mathrm{L})(1)$ \\
\hline Pulmonary edema (radiological) & Hyperlactatemia \\
\hline Abnormal bleeding & Hyperparasitemia $(\geq 2 \%)$ \\
\hline Jaundice & - \\
\hline Hemoglobinuria & - \\
\hline Adapted from Guidelines for the Treatment of Malaria, World Health Organization, $2010(7)$. \\
\hline
\end{tabular}


Severe malaria is usually due to $P$. falciparum infection, although it can also occur with $P$. knowlesi, and $P$. vivax can occasionally lead to severe disease.

3) Where was the infection acquired?

Appendix I of the Canadian Recommendations for the Prevention and Treatment of Malaria Among International Travellers shows a country-by-country and regional characterization of malaria transmission areas (4). Malarial parasites in most of the world are drug resistant. When in doubt, treat all $P$. falciparum malaria as drug resistant.

\section{Managing severe or complicated malaria}

Severe or complicated malaria, or the inability to tolerate oral therapy, requires urgent, parenteral therapy and intensive medical management (especially in the case of children), ideally in an ICU. If possible, consult with an infectious or tropical disease expert when managing a patient with severe falciparum malaria.

The primary objective of treatment is to prevent death. Prevention of neurological deficits is also an important objective for cerebral malaria. There are several treatments:

- Parenteral artesunate is the WHO-recommended first-line treatment for severe $P$. falciparum malaria.

- Parenteral quinine can be used to treat severe or complicated malaria when parenteral artesunate is not available and is the preferred drug if the only indication for parenteral therapy is intolerance to oral therapy.

- Parenteral artesunate and quinine are available 24 hours per day through the Canadian Malaria Network (30).

- Follow parenteral administration of artesunate or quinine with oral therapy using one of the following medications:

- Atovaquone-proguanil (unless used as malaria chemoprophylaxis);

- doxycycline (unless used as malaria chemoprophylaxis; contraindications: pregnancy, breastfeeding, age $<8$ years) $(7)$;

- clindamycin (only if the patient is unable to take doxycycline or atovaquone-proquanil).

Table 2 identifies the common antimalarial drugs and their indications.

Table 2: Recommendations for common antimalarial drugs

\begin{tabular}{|l|l|l|}
\hline Intravenous artesunate & $\begin{array}{l}\text { Indication } \\
\text { First-line treatment of severe falciparum } \\
\text { malaria }(3,7,31) \text { or if intravenous quinine } \\
\text { is not tolerated. }\end{array}$ & $\begin{array}{l}\text { Additional notes } \\
\text { Follow parenteral artesunate with a full } \\
\text { (Malarone }{ }^{\circledR} \text { ) or doxycycline (clindamycin } \\
\text { in pregnant women or children < } 8 \text { years) } \\
\text { or artemisinin-based combination } \\
\text { therapy. }\end{array}$ \\
& $\begin{array}{l}\text { Patients treated with IV artesunate } \\
\text { should have weekly CBC x } 4 \text { done. As } \\
\text { well they should be counselled to report } \\
\text { signs of hemolysis such as dark urine, } \\
\text { yellowing of the skin or whites of the } \\
\text { eyes, fever, abdominal pain, pallor, } \\
\text { fatigue, shortness of breath and/or chest } \\
\text { pain. }\end{array}$ \\
\hline $\begin{array}{l}\text { Oral artemisinin } \\
\text { combination therapy } \\
\text { (not yet available in Canada) }\end{array}$ & $\begin{array}{l}\text { Uncomplicated falciparum malaria or } \\
\text { when the causative species has not been } \\
\text { identified. }\end{array}$ & \\
\hline
\end{tabular}




\begin{tabular}{|c|c|c|}
\hline & Indication & Additional notes \\
\hline $\begin{array}{l}\text { Atovaquone-proguanil } \\
\text { Trade Name: Malarone }\end{array}$ & $\begin{array}{l}\text { First-line treatment of acute, } \\
\text { uncomplicated } P \text {. falciparum malaria and } \\
P \text {. vivax malaria } \\
\text { Uncomplicated malaria in adults and in } \\
\text { children } \geq 11 \mathrm{~kg} \text {. }\end{array}$ & \\
\hline $\begin{array}{l}\text { Chloroquine (or } \\
\text { hydroxychloroquine) } \\
\text { Trade Name: Novo- } \\
\text { Chloroquine (or Plaquenil }{ }^{\circledR} \\
\text { Apo-Hydroxyquine, Gen- } \\
\text { Hydroxychloroquine) }\end{array}$ & $\begin{array}{l}\text { Chloroquine-sensitive } P \text {. falciparum, } P \text {. } \\
\text { vivax, } P \text {. ovale, } P \text {. malariae and } P \text {. } \\
\text { knowlesi infections. }\end{array}$ & Suitable for all ages and in pregnancy. \\
\hline $\begin{array}{l}\text { Clindamycin } \\
\text { Trade Name: (Dalacin } \mathrm{C}^{\circledR} \text { ), } \\
\text { Apo-Clindamycin, Novo- } \\
\text { Clindamycin }\end{array}$ & $\begin{array}{l}\text { Clindamycin is combined with quinine to } \\
\text { treat chloroquine- or mefloquine-resistant } \\
P . \text { falciparum malaria in pregnant } \\
\text { women, children ( }<8 \text { years) and } \\
\text { tetracycline-intolerant adults when } \\
\text { artemisinin-derivatives are unavailable. }\end{array}$ & $\begin{array}{l}\text { Less effective than doxycycline or } \\
\text { atovaquone-proguanil. }\end{array}$ \\
\hline $\begin{array}{l}\text { Doxycycline } \\
\text { Trade Name: Vibra-Tabs }{ }^{\mathrm{TM}} \text {, } \\
\text { Apo-Doxy, Doxycin, Novo- } \\
\text { Doxylin, Nu-Doxycycline, } \\
\text { ratio-Doxycycline }\end{array}$ & $\begin{array}{l}\text { To prevent and treat chloroquine- } \\
\text { resistant } P \text {. falciparuml. }\end{array}$ & $\begin{array}{l}\text { Contraindicated in pregnancy, while } \\
\text { breastfeeding and in children aged }<8 \\
\text { years of age. }\end{array}$ \\
\hline Quinine and quinidine & $\begin{array}{l}\text { Parenteral quinine is used to treat severe } \\
\text { or complicated malaria when parenteral } \\
\text { artesunate is unavailable and is the first- } \\
\text { line drug for those who cannot take oral } \\
\text { therapy and do not meet any criteria for } \\
\text { severe disease. } \\
\text { Oral treatment using quinine with } \\
\text { doxycycline or clindamycin is indicated } \\
\text { for uncomplicated falciparum malaria and } \\
\text { as step-down therapy after parenteral } \\
\text { treatment of complicated malaria. }\end{array}$ & $\begin{array}{l}\text { The Canadian Malaria Network } \\
\text { recommends reserving artesunate for } \\
\text { those with severe malaria (as defined by } \\
\text { the WHO) and using parenteral quinine } \\
\text { in those who do not tolerate oral therapy } \\
\text { or are vomiting. } \\
\text { Parenteral quinidine should only be used } \\
\text { if the two first-line drugs are unavailable; } \\
\text { cardiac monitoring is required. }\end{array}$ \\
\hline $\begin{array}{l}\text { Primaquine } \\
\text { Trade Name: Primaquine } \\
\text { (primaquine phosphate) }\end{array}$ & $\begin{array}{l}\text { Used to prevent relapse due to } P \text {. vivax } \\
\text { or } P \text {. ovale infection. } \\
\text { Used as a "radical cure" to reduce the } \\
\text { risk of relapse after the treatment of } \\
\text { symptomatic } P \text {. vivax or } P \text {. ovale } \\
\text { infection. }\end{array}$ & $\begin{array}{l}\text { Contraindicated in people with severe } \\
\text { G6PD deficiencies, in pregnancy and in } \\
\text { nursing mothers if the infant is G6PD } \\
\text { deficient. }\end{array}$ \\
\hline
\end{tabular}

If parenteral artesunate or quinine is indicated but is not available for more than an hour, start quinine orally (after a dose of gravol) or by nasogastric tube until the parenteral drug is available. Patients should have at least 24 hours of parenteral therapy before switching to oral therapy.

Frequent clinical observations should monitor vital signs and assess respiratory rate and pattern, coma score and urine output. Use rapid stick tests to monitor blood glucose at least every four hours. Treat seizures promptly with benzodiazepines (7). Clinically assess all patients daily until fever ends and whenever symptoms recur; for $P$. falciparum cases, repeat malaria smears daily until these are negative.

In cases with high parasitemia ( $\geq 10 \%$ ), exchange transfusion to remove infected red blood cells and toxic mediators from the circulation and reduce the parasite load may be beneficial $(8,32)$. 


\section{Managing uncomplicated falciparum malaria}

Uncomplicated falciparum malaria refers to symptomatic malaria with no evidence of severe disease or of vital organ dysfunction. Uncomplicated malaria is treated to cure the infection and prevent progression to severe disease. When choosing treatment regimens, consider drug tolerability, adverse effects of drugs and the speed of the therapeutic response.

The treatments of choice for uncomplicated $P$. falciparum malaria are as follows:

- $\quad$ Oral chloroquine (ONLY for those with travel to exclusively chloroquine-sensitive areas);

- Oral atovaquone-proguanil (7);

- Oral quinine combined with oral doxycycline simultaneously or sequentially, starting with quinine; if doxycycline is contraindicated, administer oral quinine and clindamycin, simultaneously or sequentially (33-34);

- Combination therapy with an artemisinin derivative (not yet available in Canada) (7).

\section{Managing non-falciparum malaria}

Conduct a clinical assessment daily until fever ends and whenever symptoms recur. For $P$. vivax infections, recurrence of asexual parasitemia less than 30 days after treatment suggests chloroquine-resistant $P$. vivax; recurrence after 30 days suggests primaquine-resistant $P$. vivax.

The treatment of choice for non-falciparum malaria outside of chloroquine-resistant regions continues to be chloroquine. The optimal chemoprophylaxis or treatment of $P$. vivax acquired in chloroquine-resistant regions is unknown, although a seven-day course of quinine is often required to cure $P$. vivax infection.

\section{Managing undefined malaria}

If fever, travel history and initial laboratory findings (low white blood count and/or platelets) suggest a diagnosis of malaria but the malaria smear is delayed for more than two hours, start a therapeutic antimalarial that is effective for the area of travel/acquisition.

\section{Managing relapses}

$P$. vivax and $P$. ovale have a persistent liver phase (hypnozoites) that is responsible for relapses for months or even years after exposure, even in the absence of primary symptomatic malaria infection. None of the currently recommended chemoprophylaxis regimens will prevent relapses due to $P$. vivax or $P$. ovale.

To reduce the risk of relapse after the treatment of symptomatic $P$. vivax or $P$. ovale infection, primaquine is indicated to provide a "radical cure". Initiate the primaquine radical cure after the acute febrile illness is over, but so that it overlaps with the blood schizonticide (i.e. chloroquine or quinine) (7).

Primaquine is contraindicated in people with severe G6PD deficiencies and in pregnancy. Prevent relapses in pregnancy with weekly doses of chloroquine until after delivery, when primaquine can be safely used for mothers with normal G6PD levels unless they are breastfeeding. Nursing mothers should only use primaquine if the infant has been tested and is not G6PD deficient.

$P$. knowlesi, a threat in southeast Asia, can be confused microscopically as $P$. malariae except that it has higher (> 1\%) parasitemia. Systemic symptoms and complications can mimic $P$. falciparum malaria. Treatment with chloroquine is reportedly effective, but systemic symptoms and complications similar to those of hyperparasitemic $P$. falciparum infections require very close monitoring and careful management $(25,35)$, and, potentially, parenteral therapy with artesunate.

\section{Self-treatment of presumptive malaria}

Self-treatment may be a life-saving measure for 24 hours while medical attention is sought. Travellers to high-risk regions (e.g. sub-Saharan Africa, where $90 \%$ of global malaria morbidity and mortality occurs) should never rely 
exclusively on self-treatment $(9,21,23,25)$. The signs and symptoms of malaria are nonspecific, and malaria cannot be definitively diagnosed without a laboratory test $(10,37,38)$.

Travellers at risk of malaria and unable to access medical care within 24 hours for adequate malaria treatment drugs should carry effective medication for self-treatment of presumptive malaria.

- In chloroquine-sensitive regions, self-treat with chloroquine and then resume or start chloroquine prophylaxis (9-11).

- In chloroquine- and/or chloroquine- and mefloquine-resistant $P$. falciparum regions, self-treatment requires a different drug if the traveller is taking a chemoprophylactic agent. Ideally, this should have been brought from a country with high standards of quality control to minimize the likelihood of counterfeit products:
$\circ$ Atovaquone-proguanil
o oral quinine and doxycycline $(10-11,13)$
$\circ$ artemether-lumefantrine

\section{Contraindicated malaria drugs}

A number of antimalarials are contraindicated for the treatment of malaria (self-treatment or otherwise):

- mefloquine

- $\quad$ pyrimethamine-sulfadoxine (Fansidar)

- mefloquine-Fansidar

- halofantrine

- chloroquine-Fansidar

\section{Summary}

A summary of the key changes made to the 2014 Guidelines are noted in Table 3.

Table 3: Summary of key additions and changes to the 2014 Guidelines pertaining to the diagnosis and treatment of malaria (4)

\section{Additions}

1. The management of severe malaria has been updated to include new information on the use of exchange transfusion (see Chapter 7).

2. A new "Malaria Card" that can be given to travellers with information about their malaria chemoprophylaxis and an important reminder to seek medical attention in the event of a fever illness after travel.

\section{Changes}

1. Chapter 8, "Drugs for the Prevention and Treatment of Malaria," includes up-to-date information on pediatric dosing of atovaquone/proguanil; general updates to Table 8.11: Drugs (generic and trade name) for the treatment and prevention of malaria. Revisions have also been made to the following sub-sections: artemisinins, chloroquine and quinine/quinidine.

2. Change in parasitemia level to define hyperparasitemia with severe malaria: now $\geq 2 \%$ from $5 \%$ in nonimmune travellers. 


\section{Conclusions}

Malarial management depends on rapid identification of the disease, as well as identification of the malaria species and level of parasitemia. Severe or complicated malaria requires admission to hospital. Uncomplicated malaria is treated to cure the infection and prevent progression to severe disease. Treatment varies according to the species of malaria, severity and where the malaria was acquired.

\section{Acknowledgements}

CATMAT acknowledges and appreciates the contribution of Joanna Odrowaz, Elspeth Payne to the development of the summaries and Manisha Kulkarni for her contribution to the statement.

CATMAT Members: Boggild A, Brophy J, Bui YG, Crockett M, Ghesquiere W, Greenaway C, Henteleff A, Libman $M$, Teitelbaum $P$ and McCarthy A (Chair).

Liaison members: Hui C (Canadian Paediatric Society) and Gershman M (US Centers for Disease Control and Prevention).

Ex-officio members: Marion D (Canadian Forces Health Services Centre, Department of National Defence), McDonald P (Division of Anti-Infective Drugs, Health Canada), Schofield S (Directorate of Force Health Protection, Department of National Defence), and Tepper M (Directorate of Force Health Protection, Department of National Defence).

Member Emeritus: Jeanes CWL.

\section{Conflict of interest}

There are no conflicts of interest to declare.

\section{Funding}

This work was supported by the Public Health Agency of Canada.

\section{References}

(1) McCarthy AE, Plourde P, Kuhn S, Bodie M. Parenteral quinine for severe malaria: five year surveillance data from the Canadian Malaria Network. 10th Conference of the International Society of Travel Medicine 2007; Abstract No. FC02.01.

(2) Murphy GS, Oldfield EC,3rd. Falciparum malaria. Infect Dis Clin North Am 1996 Dec;10(4):747-775.

(3) Sinclair D, Donegan S, Lalloo DG. Artesunate versus quinine for treating severe malaria. Cochrane Database Syst Rev 2011 Mar 16;(3):CD005967. doi(3):CD005967.

(4) Committee to Advise on Tropical Medicine and Travel. Canadian Recommendations for the Prevention and Treatment of Malaria (in press). http://publications.gc.ca/site/eng/463465/publication.html.

(5) Committee to Advise on Tropical Medicine and Travel. Summary of recommendations for the prevention of malaria by the Committee to Advise on Tropical Medicine and Travel (CATMAT). Can Commun Dis Rep 2014;40(7).

(6) Leslie T, Mayan I, Mohammed N, Erasmus P, Kolaczinski J, Whitty CJ, et al. A randomised trial of an eightweek, once weekly primaquine regimen to prevent relapse of Plasmodium vivax in Northwest Frontier Province, Pakistan. PLoS One 2008 Aug;3(8):e2861.

(7) World Health Organization. Guidelines for the treatment of malaria, Second edition. 2010. 
(8) Riddle MS, Jackson JL, Sanders JW, Blazes DL. Exchange transfusion as an adjunct therapy in severe Plasmodium falciparum malaria: a meta-analysis. Clin Infect Dis 2002 May;34(9):1192-1198.

(9) Schlagenhauf $P$, Petersen E. Standby emergency treatment of malaria in travelers: experience to date and new developments. Expert Rev Anti Infect Ther 2012 May;10(5):537-546.

(10) Nothdurft HD, Jelinek T, Pechel SM, Hess F, Maiwald H, Marschang A, et al. Stand-by treatment of suspected malaria in travellers. Trop Med Parasitol 1995 Sep;46(3):161-163.

(11) Schlagenhauf P, Steffen R. Stand-by treatment of malaria in travellers: a review. J Trop Med Hyg 1994 Jun;97(3):151-160.

(12) Newton P, Proux S, Green M, Smithuis F, Rozendaal J, Prakongpan S, et al. Fake artesunate in southeast Asia. Lancet 2001 Jun;357(9272):1948-1950.

(13) Cockburn R, Newton PN, Agyarko EK, Akunyili D, White NJ. The global threat of counterfeit drugs: why industry and governments must communicate the dangers. PLoS Med 2005 Apr;2(4):e100.

(14) Prasad K, Garner P. Steroids for treating cerebral malaria. Cochrane Database Syst Rev 2000;(2):CD000972.

(15) Weinke T, Trautmann M, Held T, Weber G, Eichenlaub D, Fleischer K, et al. Neuropsychiatric side effects after the use of mefloquine. Am J Trop Med Hyg 1991 Jul;45(1):86-91.

(16) Roll Back Malaria Department, WHOand UNICEF. World Malaria Report. 2005.

(17) Luxemburger C, Price RN, Nosten F, Ter Kuile FO, Chongsuphajaisiddhi T, White NJ. Mefloquine in infants and young children. Ann Trop Paediatr 1996 Dec;16(4):281-286.

(18) Chen LH, Wilson ME, Schlagenhauf P. Controversies and misconceptions in malaria chemoprophylaxis for travelers. JAMA 2007 May;297(20):2251-2263.

(19) Mali S, Kachur SP, Arguin PM, Division of Parasitic Diseases and Malaria, Center for Global Health, Centers for Disease Control and Prevention (CDC). Malaria surveillance--United States, 2010. MMWR Surveill Summ 2012 Mar;61(2):1-17.

(20) Svenson JE, Gyorkos TW, MacLean JD. Diagnosis of malaria in the febrile traveler. Am J Trop Med Hyg 1995;53(5):518-521.

(21) Swales CA, Chiodini PL, Bannister BA, Health Protection Agency Advisory Committee on Malaria Prevention in UK Travellers. New guidelines on malaria prevention: a summary. J Infect 2007 Feb;54(2):107-110.

(22) Reyburn H, Mbatia R, Drakeley C, Carneiro I, Mwakasungula E, Mwerinde O, et al. Overdiagnosis of malaria in patients with severe febrile illness in Tanzania: a prospective study. BMJ 2004 Nov;329(7476):1212.

(23) Quach C, Kain K, MacPherson D, Mendelson J, MacLean J. Malaria deaths in Canadian travellers. Can Commun Dis Rep 1999 Mar;25(6):50-53.

(24) Cox-Singh J, Davis TM, Lee KS, Shamsul SS, Matusop A, Ratnam S, et al. Plasmodium knowlesi malaria in humans is widely distributed and potentially life threatening. Clin Infect Dis 2008 Jan;46(2):165-171.

(25) Centers for Disease Control and Prevention (CDC). CDC Health Information for International Travel 2012. New York: Oxford University Press; 2012.

(26) Chen LH, Wilson ME, Schlagenhauf P. Prevention of malaria in long-term travelers. JAMA 2006 Nov;296(18):2234-2244.

(27) Farcas GA, Soeller R, Zhong K, Zahirieh A, Kain KC. Real-time polymerase chain reaction assay for the rapid detection and characterization of chloroquine-resistant Plasmodium falciparum malaria in returned travelers. Clin Infect Dis 2006 Mar;42(5):622-627.

(28) Hawkes M, Kain KC. Advances in malaria diagnosis. Expert Rev Anti Infect Ther 2007 Jun;5(3):485-495. 
(29) Farcas GA, Zhong KJ, Mazzulli T, Kain KC. Evaluation of the RealArt Malaria LC real-time PCR assay for malaria diagnosis. J Clin Microbiol 2004 Feb;42(2):636-638.

(30) Public Health Agency of Canada. Medical Access to Quinine for Malaria Treatment Streamlined in Canada through the Canadian Malaria Network. http://www.phac-aspc.gc.ca/tmp-pmv/quinine/index-eng.php. Accessed March 6, 2014.

(31) Dondorp A, Nosten F, Stepniewska K, Day N, White N, South East Asian Quinine Artesunate Malaria Trial (SEAQUAMAT) group. Artesunate versus quinine for treatment of severe falciparum malaria: a randomised trial. Lancet 2005 Aug 27-Sep 2;366(9487):717-725.

(32) Nieuwenhuis JA, Meertens JH, Zijlstra JG, Ligtenberg JJ, Tulleken JE, van der Werf TS. Automated erythrocytapheresis in severe falciparum malaria: a critical appraisal. Acta Trop 2006 Jul;98(3):201-206.

(33) World Health Organization. International travel and health. Geneva, Switzerland: World Health Organization; 2012.

(34) Griffith KS, Lewis LS, Mali S, Parise ME. Treatment of malaria in the United States: a systematic review. JAMA 2007 May;297(20):2264-2277.

(35) White NJ. Plasmodium knowlesi: the fifth human malaria parasite. Clin Infect Dis 2008 Jan;46(2):172-173.

(36) Singh B, Kim Sung L, Matusop A, Radhakrishnan A, Shamsul SS, Cox-Singh J, et al. A large focus of naturally acquired Plasmodium knowlesi infections in human beings. Lancet 2004 Mar;363(9414):1017-1024.

(37) Schlagenhauf P, Steffen R, Tschopp A, Van Damme P, Mittelholzer ML, Leuenberger H, et al. Behavioural aspects of travellers in their use of malaria presumptive treatment. Bull World Health Organ 1995;73(2):215-221.

(38) World Health Organization. WHO Expert Committee on Malaria: Twentieth Report. 2000 Geneva, Switzerland;892. 